\title{
Adaptando o Espaço para Criança: Utilizando os Critérios Montesorianos para Promoção de uma Infância Autônoma
}

\author{
Adapting the Space for Children: Using the Montesorian Criteria for the Promotion of \\ an Autonomous Childhood
}

PENA, Douglas Jônatas Soares; Mestrando; Universidade Federal da Bahia; douglas.pena18@gmail.com

FACTUM, Ana Beatriz Simon; Doutora; Universidade do Estado da Bahia e PPGAV-UFBA; biasimon@gmail.com

\begin{abstract}
Resumo
Apesar de algumas indústrias de móveis buscarem aproximar a estética do mobiliário com o imaginário infantil, poucos móveis possuem essa característica assim também como a produção de móveis proporcionais a escala da criança. A presente pesquisa objetivou estabelecer recomendações para a organização espacial do quarto infantil com base nos princípios montessorianos, no desejo da criança e em suas referências antropométricas. Foram feitas pesquisas para entender mais do universo infantil e seu desenvolvimento, aliado a metodologia de Maria Montessori e os desejos das crianças, permitindo que estes fossem incorporados no projeto de quarto infantil. Depois de realizar um levantamento de dados antropométricos foram produzidas três alternativas com metragens diferentes, com o propósito de demonstrar que é possível atender aos diversos padrões de moradia. Por fim, uma das recomendações mais importantes é ouvir as sugestões e desejos da criança permitindo que sejam atendidos.
\end{abstract}

Palavras-chave: Design de ambientes; Quarto infantil; recomendações Montessorianas; desejos da criança.

\begin{abstract}
:
Although some furniture industries try to approach the aesthetics of furniture with the children's imagination, few furniture have this characteristic as well as the production of furniture proportional to the scale of the child. The present research aimed to establish recommendations for the spatial organization of the children's room based on the Montessor principles, the child's desire and anthropometric references. Research was done to understand more about the infant universe and its development, allied to the methodology of Maria Montessori and the children's wishes, allowing them to be incorporated into the children's bedroom project. After performing an anthropometric data collection, three alternatives were produced with different lengths, in order to demonstrate that it is possible to meet the different housing standards. Finally, one of the most important recommendations is to listen to the child's suggestions and wishes, allowing them to be cared for.
\end{abstract}

Keywords: Environmental design; Children'sroom, Montessori recommendations, child'swishes. 


\section{Introdução}

Este artigo apresenta os resultados do Trabalho de Conclusão de Curso (TCC), desenvolvido no âmbito do curso de Design da Universidade do Estado da Bahia (UNEB).

A indústria moveleira tem se preocupado cada vez mais em produzir móveis infantis que tenham características lúdicas como, por exemplo, camas em formatos de carros, animais, castelos, etc., com o intuito de tornar o quarto das crianças mais divertido. Contudo as crianças menores nem sempre são contempladas, pois a escala dos móveis mais acessíveis financeiramente no mercado, em geral, não está adequada a elas. Embasado no método de Maria Montessori, uma importante educadora que desenvolveu um modelo educacional caracterizado por uma ênfase na independência, liberdade e respeito pelo desenvolvimento natural da criança, quartos infantis estão sendo projetados para auxiliar neste desenvolvimento. Segundo Salomão (2012) " "O primeiro passo para a montagem de um quarto infantil é adotar o ponto de vista da criança.Aquilo que ela puder acessar deve ficar ao nível de suas mãos". Os brinquedos da criança devem ser guardados por ela em uma prateleira baixa ao seu alcance, assim também como suas roupas devem estar disponíveis para seu acesso. Contudo, este modelo de quarto, projetado para promover a autonomia das crianças ainda é pouco visto na maioria das casas brasileiras. $\mathrm{O}$ que gera a questão de pesquisa ou de projeto: Como os critérios Montessorianos podem ser inseridos na organização de um quarto infantil de forma que atenda às necessidades da criança e promova sua autonomia de forma segura neste ambiente? A partir dessa questão problema foi construído objetivo geral dessa pesquisa: estabelecer recomendações para a organização espacial do quarto infantil com base nos princípios Montessorianos, no desejo da criança e em suas referências antropométricas.

Foram eleitas duas metodologias, cada uma com características importantes para este projeto. A primeira foi à metodologia de Design proposto por Flávio Anthero (2006) composta por três etapas: preconcepção, concepção e pós-concepção. Por isso apresenta os seguintes itens: a problematização, a fundamentação teórica, levantamento de mobiliário, levantamento de necessidades, estudos antropométricos e geração de alternativas. E adotou-se a metodologia de Design Participativo (DP), na qual a participação do usuário no projeto e avaliação vai além de uma ação meramente consultiva. Elegendo o DP houve a necessidade de buscar procedimentos no processo metodológico que dessem a possibilidade das crianças serem escutadas. Para isso,foi utilizada a metodologia de pesquisa proposta pela professora da Faculdade de Educação da Universidade de São Paulo (USP) Márcia Gobbi, sendo um dos capítulos do livro "Por uma Cultura da Infância: Metodologias de Pesquisa com Crianças" organizado por Ana Lúcia Goulart de Faria, Zeila de Brito FabriDemartini e Patrícia Dias Prado.

Este artigo é composto por esta introdução, seguido dos seguintes itens: Desenvolvimento da criança e sua relação com o espaço; Levantamento de necessidades; Adotando o ponto de vista da criança; Levantamento de dados antropométricos para o dimensionamento do mobiliário para quarto infantil e Geração de alternativas. Para o seu fechamento tem-se as considerações finais.

\footnotetext{
${ }^{1}$ Gabriel Merched Salomão é o responsável pelo conteúdo do site Lar Montessori que "foi criado para ajudar pais e mães a obter os benefícios de uma educação montessoriana para seus filhos, em casa". Disponível em https://larmontessori.com/about/. Acesso em 28/05/2016.
} 


\title{
2. Desenvolvimento da criança e sua relação com o espaço
}

Há algum tempo estudiosos e pesquisadores procuram teorias a respeito do desenvolvimento da criança, como elas pensam e aprendem e debates e estudos continuam sendo produzidos.

Este projeto tinha inicialmente como público-alvo crianças de 0 a 6 anos, no entanto em conversa com a Professora Sueli Rocha ${ }^{2}$, foi sugerido trabalhar com crianças a partir de 3 anos, pois é nessa idade que eles começam a desenvolver mais sua independência, podem subir escadas sozinhas alternando os pés, começam a conversar e já possuem uma boa compreensão. Por isso, o público estudado e atendido são as crianças de 3 a 6 anos.

O psicólogo bielo-russo Lev Vygotsky, enfatiza que a aquisição de conhecimentos se dá pela interação do sujeito com o meio. Ele acredita que isso acontece através do processo chamado de mediação que é a relação interpessoal de troca com o meio.

Vygotsky afirma no seu livro "A formação social da mente" (1996) que o fator biológico da espécie não é suficiente para realização de uma tarefa se o indivíduo não interage com ambientes e práticas específicas que ofereçam esta aprendizagem. Existem sim as fases de desenvolvimento, mas não podemos acreditar que a criança se desenvolverá por si só com o tempo, pois esta não tem repertório suficiente para percorrer sozinha o caminho do desenvolvimento, que dependerá das suas aprendizagens mediante as experiências vivenciadas.

\begin{abstract}
Para Vygotsky, o processo de aprendizagem deve ser olhado por uma ótica prospectiva, ou seja, não se deve focalizar o que a criança aprendeu, mas sim o que ela está aprendendo. Em nossas práticas pedagógicas, sempre procuramos prever em que tal ou qual aprendizado poderá ser útil àquela criança, não somente no momento em que é ministrado, mas para além dele. É um processo de transformação constante na trajetória das crianças. As implicações desta relação entre ensino e aprendizagem para o ensino escolar estão no fato de que este ensino deve se concentrar no que a criança está aprendendo, e não no que já aprendeu. Vygotksy firma está hipótese no seu conceito de zona de desenvolvimento proximal (ZDP). (Creche Fiocruz, 2004, apud RABELLO e PASSOS, 2007).
\end{abstract}

Segundo Buitoni (2009) diferente do mundo dos adultos, as crianças percebem o espaço sempre como ambiente relacionado às suas sensações: espaço-alegria, espaço-medo, espaçoproteção, os espaços onde elas experimentam liberdade ou opressão. "É no espaço físico que a criança estabelece a relação com o mundo e com as pessoas e ao fazê-lo esse espaço material se qualifica. Ela deixa de ser um material construído ou organizado para se embeber da atmosfera que as relações ajudam a estabelecer" (LIMA, 1989 apud BUITONI, 2009).

Aliado a estas duas evidencias do desenvolvimento infantil, tem-se o Método Montessoriano descrito por Salomão (2012) como um conjunto de teorias, práticas e materiais didáticos criados ou idealizados inicialmente por Maria Montessori, enfatizando que o ponto mais importante do método, não é tanto seu material ou sua prática, mas a possibilidade criada pela utilização dele, de se libertar a verdadeira natureza do indivíduo, permitindo que esta possa ser observada, compreendida, e para que a educação se desenvolva com base na evolução da criança. Este método tem sido utilizado em escolas, desde o berçário até o Ensino Médio, em escolas especiais, clínicas de psicopedagogia e lares por todo o mundo. Tem sido aplicado também em

\footnotetext{
${ }^{2}$ Professora da Escola Brinquedoteca Arte e Vida, nos recebeu e nos orientou na atividade com as crianças.
} 
Design de Interiores na criação de quartos infantis, preparados para promover autonomia e liberdade à criança.

\section{Levantamento de necessidades}

Para planejar o ambiente, neste caso um quarto infantil, que melhor solucione a problemática projetual, foi necessário fazer um levantamento de necessidades. Nesse levantamento utilizou-se os critérios para mobiliário infantil sugerido no método Montessori, contudo antes de definir qualquer escolha,considerou-se indispensável a escuta das crianças, ouvir seus desejos, pois isso a aproximará ainda mais deste ambiente, fazendo com que ela tenha satisfação em estar nele, sinta-se confortável e segura. É importante que o quarto seja funcional, composto por poucos móveis, para permitir maior área de circulação. Os brinquedos devem ser oferecidos em rodízios para atenderas fases da criança. Tudo deve estar ao alcance da vista e da mão da criança. Segue abaixo relacionado alguns critérios essenciais para um quarto Montessoriano:

- $\quad$ A cama deve ser baixa para que a criança possa explorar o cômodo, sem ajuda dos pais e com isso contribuir no seu desenvolvimento intelectual;

- $\quad$ Armário ao alcance da criança ou deixar a roupa do dia em cestas para que ela possa se vestir sozinha;

- $\quad$ O espelho deve estar à altura da criança para que ela possa se reconhecer;

- $\quad$ Estante baixa para guardar brinquedos de forma organizada;

- $\quad$ Cantinho da leitura que pode ser mesinha com cadeira de tamanho infantil ou mesmo um tapete no chão com cestinhas de livro;

- Quadros, desenhos, pinturas e objetos decorativos devem estar à uma altura que a criança possa apreciar.

\section{Adotando o ponto de vista da criança}

Para entender e contemplar o universo infantil e saber como as crianças interpretam seus quartos e como desejam que ele fosse projetado foi utilizada à metodologia proposta por Márcia Gobbi (2002), "Desenho infantil e Oralidade", ou seja, obter respostas em relação as crianças por meio dos seus desenhos. Portanto, visitou-se a Escola Brinquedoteca Arte Vida, onde foi desenvolvida uma atividade com 10 crianças de 3 a 6 anos, com a orientação de uma educadora, que fez a mediação do designer-pesquisador com os sujeitos da pesquisa.

As crianças estavam bem à vontade e desenvolveram muito bem a atividade. Foi solicitado a elas que desenhassem seus quartos e depois, que desenhassem o quarto que gostariam de ter. As atividades propostas ofereceram às crianças participantes espaço para expressarem suas ideias. Através dos desenhos foi possível perceber a representação de móveis dispostos no quarto, bem como, dos objetos e cores. Foi impressionante constatar a grande criatividade destas crianças, pois apesar de tão pequenas, possuem uma excelente noção de espaço. Ao final da atividade elas puderam expressar, também oralmente, as alterações que gostariam que fossem realizadas no quarto. Por uma questão de respeito aos sujeitos pesquisados e a vontade de seus pais que não permitiram sua identificação, tem-se abaixo alguns desenhos feitos pelas crianças identificados por números. 
Figura 1 - Desenho produzido pela Criança 1

10 Faga o desenho do seu quarto.

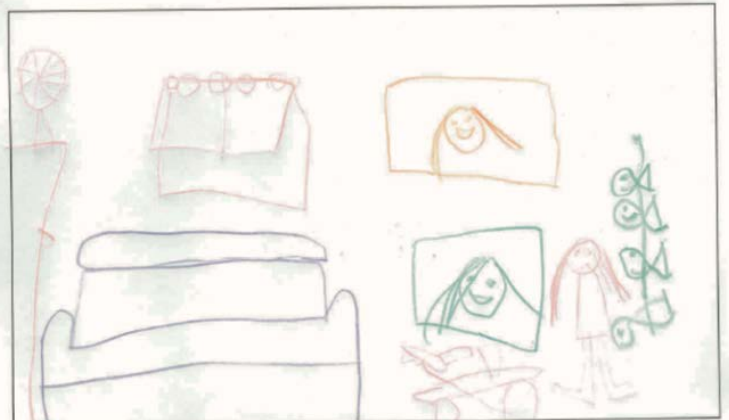

Fonte: acervo do autor, 2016.

Figura 2 - Desenho produzido pela Criança 1

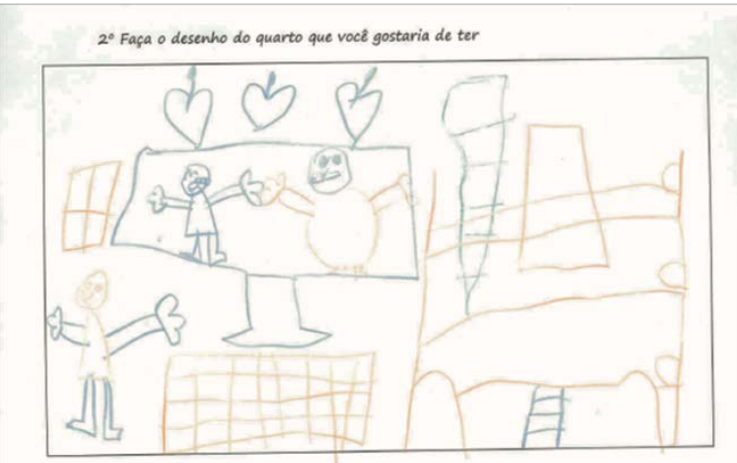

Fonte: acervo do autor, 2016.

Ao conversar com a criança 1 , ela explicou seu desenho, verbalizando que se sente muito confortável com seu quarto, com os móveis, mas disse que gostaria que tivesse um espelho grande, mais fotografias nas paredes, pois como consta no desenho há duas fotos, além de pendurar seus desenhos na parede, uma TV e um armário para guardar seus brinquedos.

Figura 3 - Desenho produzido pela Criança 2

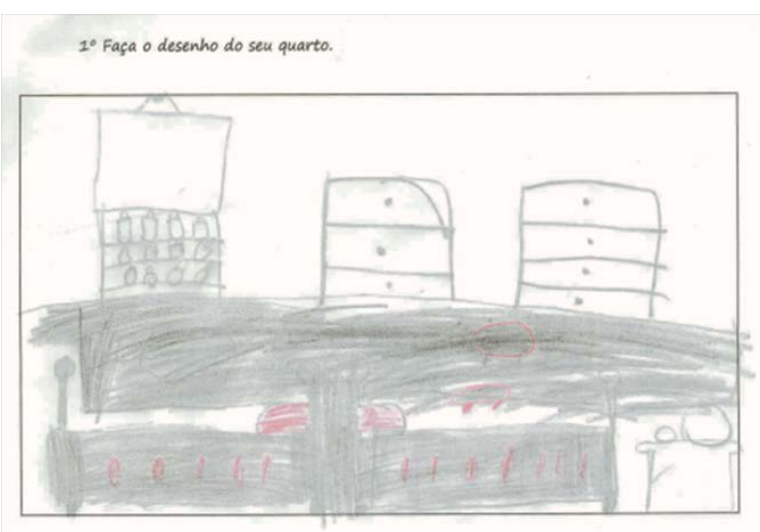

Fonte: acervo do autor, 2016. 
Figura 4 - Desenho produzido pela Criança 2

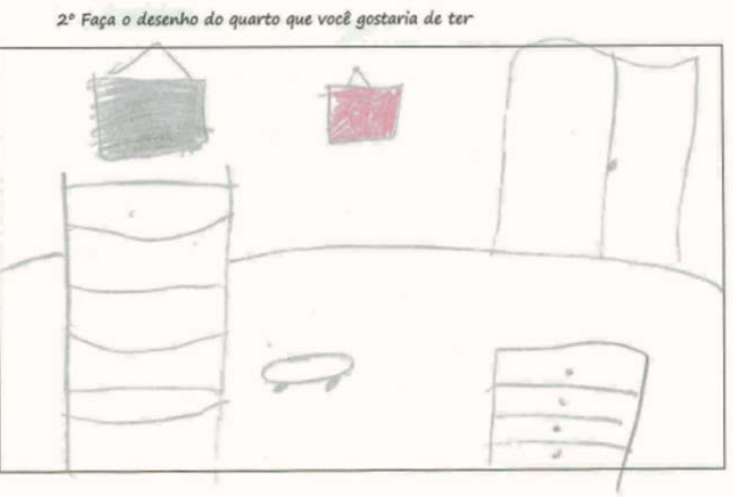

Fonte: acervo do autor, 2016.

Esta criança divide seu quarto com o irmão e informou que falta espaço para brincar neste ambiente. Sugeriu que neste quarto tivesse um beliche, um armário e uma cômoda. A substituição das duas camas por um beliche amplia o espaço de circulação, também sugeriu a colocação de quadros na parede.

Figura 5 - Desenho produzido pela Criança 3

10 Faça o desenho do seu quarto.

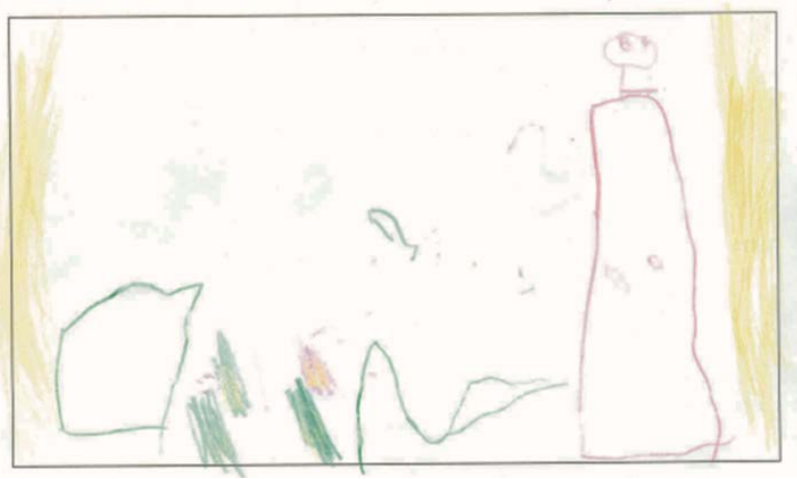

Fonte: acervo do autor, 2016.

Figura 6 - Desenho produzido pela Criança 3

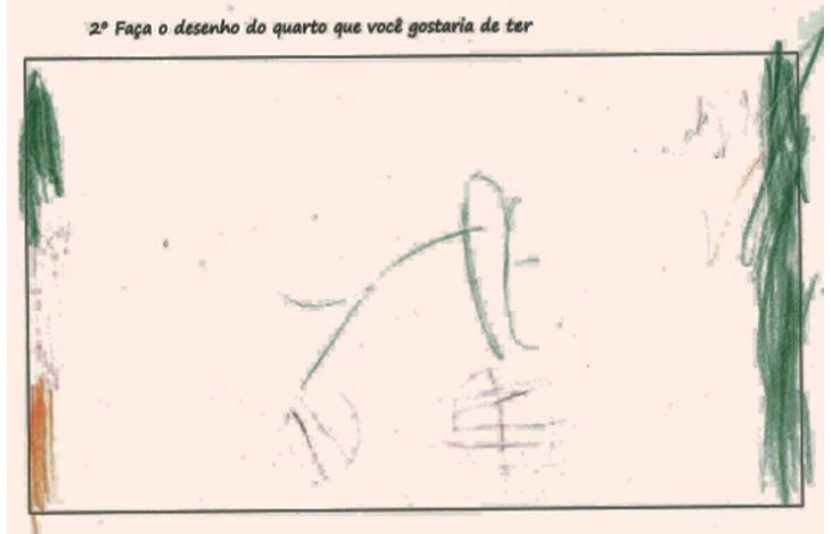


Fonte: acervo do autor, 2016.

A criança 3 era uma das mais novas a participar da atividade, apenas 3 anos, por isso vale ressaltar a importância da sua participação. Ela expressou através do desenho as cores e elementos do quarto. Em conversa com ela, soube-se que seu quatro é amarelo, porém ela gostaria que as paredes fossem coloridas.

\section{Levantamento de dados antropométricos para o dimensionamento do mobiliário para quarto infantil}

Foram levantadas as variáveis antropométricas para dimensionamento dos móveis, indispensável e essencial na projetação do quarto infantil, considerando do percentil5\% da menor mulher ao percentil 95\% do maior homem segundo Panero et al. (2003) e da menor criança (2 anos) à maior criança (6 anos) de acordo com Dreyffus (2005), de forma a atender a90\% da população usuária, conforme apresentado no quadro 1.

Quadro 1 - variáveis antropométricas para dimensionamento de mobiliário para quarto infantil

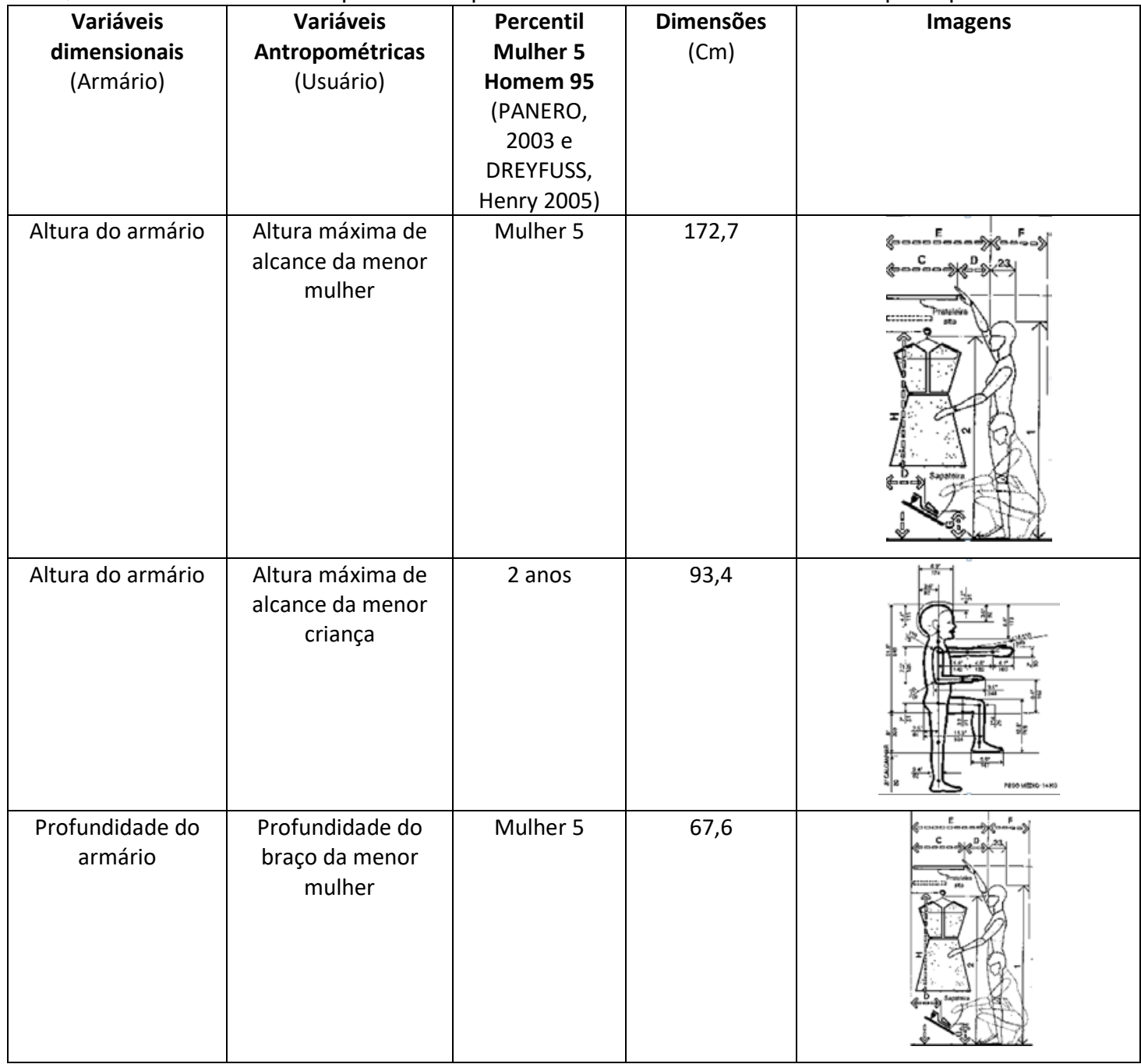




\begin{tabular}{|c|c|c|c|c|}
\hline $\begin{array}{l}\text { Profundidade do } \\
\text { armário }\end{array}$ & $\begin{array}{l}\text { Profundidade do } \\
\text { braço da menor } \\
\text { criança }\end{array}$ & 2 anos & 36,9 & 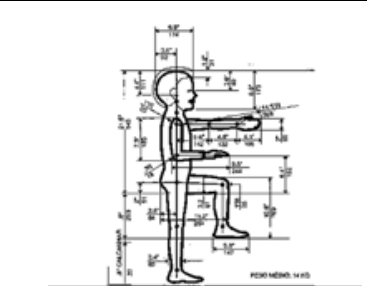 \\
\hline $\begin{array}{c}\text { Variáveis } \\
\text { dimensionais } \\
\text { (Área de } \\
\text { circulação) }\end{array}$ & $\begin{array}{c}\text { Variáveis } \\
\text { Antropométricas } \\
\text { (Usuário) }\end{array}$ & $\begin{array}{c}\text { Percentil } \\
\text { Mulher } 5 \\
\text { Homem } 95 \\
\text { (PANERO, } \\
2003 \text { ) }\end{array}$ & $\begin{array}{l}\text { Dimensões } \\
\text { (Cm) }\end{array}$ & Imagens \\
\hline Área de circulação & $\begin{array}{l}\text { Largura máxima do } \\
\text { corpo do maior } \\
\text { homem }\end{array}$ & Homem 95 & 91,4 & (1) \\
\hline $\begin{array}{c}\text { Variáveis } \\
\text { dimensionais } \\
\text { (Cama) }\end{array}$ & $\begin{array}{c}\text { Variáveis } \\
\text { Antropométricas } \\
\text { (Usuário) }\end{array}$ & $\begin{array}{c}\text { Percentil } \\
\text { Mulher } 5 \\
\text { Homem } 95 \\
\text { (DREYFUSS, } \\
\text { Henry 2005) } \\
\end{array}$ & $\begin{array}{l}\text { Dimensões } \\
(\mathrm{Cm})\end{array}$ & Imagens \\
\hline Altura da cama & $\begin{array}{l}\text { Altura da menor } \\
\text { criança sentada }\end{array}$ & 2 anos & 26,9 & 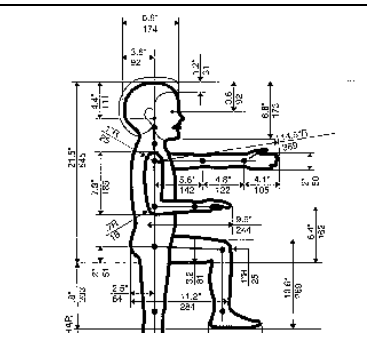 \\
\hline $\begin{array}{c}\text { Variáveis } \\
\text { dimensionais } \\
\text { (Mesa) }\end{array}$ & $\begin{array}{c}\text { Variáveis } \\
\text { Antropométricas } \\
\text { (Usuário) }\end{array}$ & $\begin{array}{c}\text { Percentil } \\
\text { Mulher } 5 \\
\text { Homem } 95 \\
\text { (DREYFUSS, } \\
\text { Henry 2005) } \\
\end{array}$ & $\begin{array}{c}\text { Dimensões } \\
(\mathrm{Cm})\end{array}$ & Imagens \\
\hline Altura da mesa & $\begin{array}{l}\text { Altura do cotovelo } \\
\text { da menor criança } \\
\text { sentada }\end{array}$ & 2 anos & 45 & 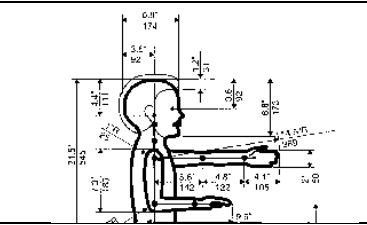 \\
\hline $\begin{array}{c}\text { Profundidade da } \\
\text { mesa }\end{array}$ & $\begin{array}{l}\text { Profundidade do } \\
\text { antebraço da maior } \\
\text { criança. }\end{array}$ & 6 anos & 60 & 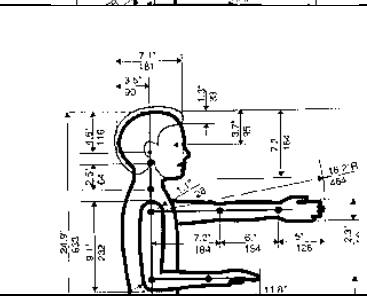 \\
\hline $\begin{array}{c}\text { Variáveis } \\
\text { dimensionais } \\
\text { (Cadeira) }\end{array}$ & $\begin{array}{c}\text { Variáveis } \\
\text { Antropométricas } \\
\text { (Usuário) }\end{array}$ & $\begin{array}{c}\text { Percentil } \\
\text { Mulher } 5 \\
\text { Homem } 95 \\
\text { (DREYFUSS, } \\
\text { Henry 2005) } \\
\end{array}$ & $\begin{array}{l}\text { Dimensões } \\
(\mathrm{Cm})\end{array}$ & Imagens \\
\hline
\end{tabular}




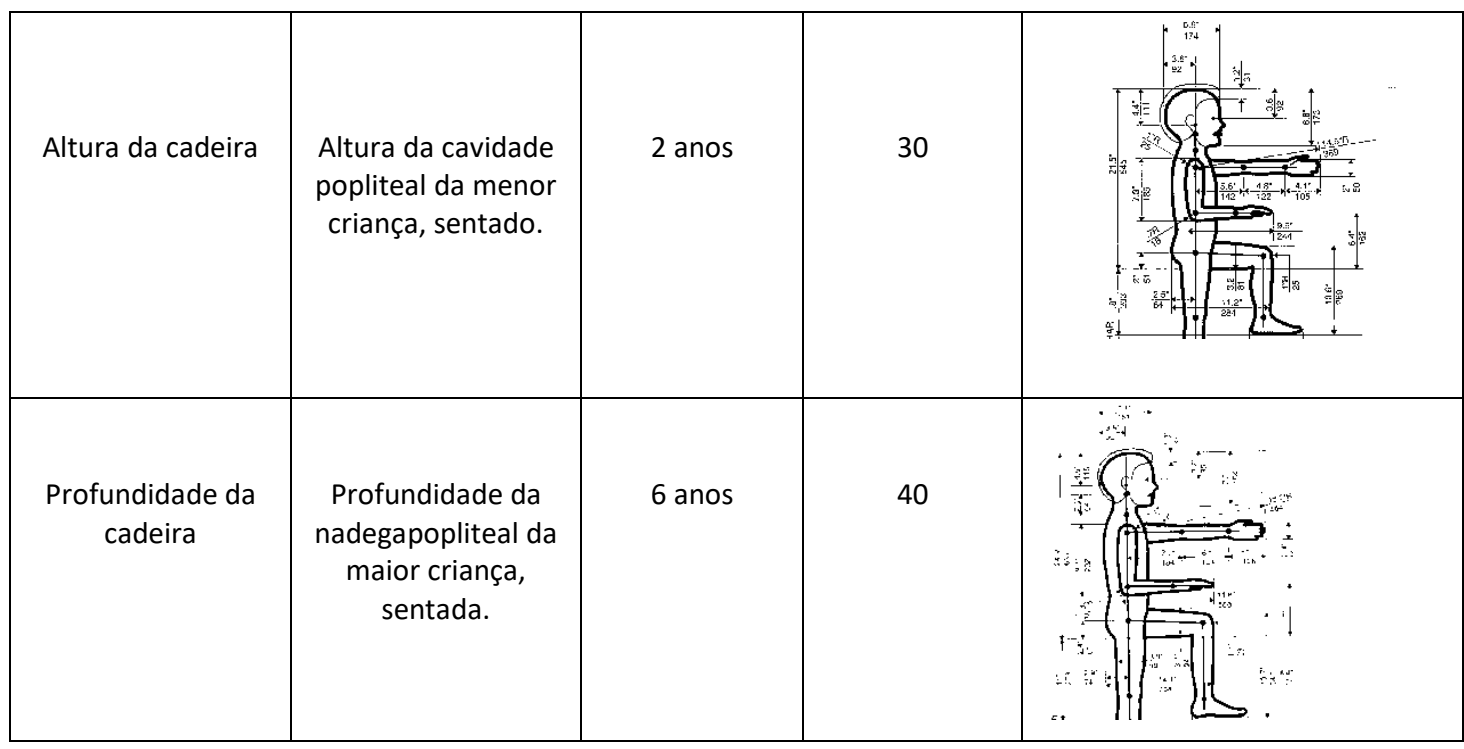

Fonte: elaborado pelo autor, com base na pesquisa realizada. Imagens de Panero, 2003.

\section{Geração de alternativas}

Desde o início do projeto houve uma preocupação em relacionar os critérios estabelecidos no método Montessoriano e os desejos da criança. Pensar nos móveis e sua organização espacial para promover liberdade e autonomia da criança foi a prioridade. Depois de realizar os estudos antropométricos identificando os alcances proporcionais a faixa etária escolhida, a partir daí, foram selecionados os móveis que respeitavam essas medidas e outros foram desenvolvidos ou adaptados para escala proporcional e adequada a faixa etária do público alvo.

Foram desenvolvidas três propostas de quarto infantil com tamanhos e perfis econômicos diferentes. Apesar das diferenças, fica demonstrado que é possível aplicar as recomendações em quartos infantis independente do seu tamanho. O ponto mais importante é permitir que a criança participe da escolha dos móveis, como tambémda decoração deste ambiente, e ter a preocupação em selecionar os móveis que atendam a escala proporcionalao tamanho da criança, afim de permitir que esta possa sozinha acessá-lo sem auxílio dos paisou de um adulto.

Dos móveis sugeridos pelos critérios estabelecidos no Método Montessoriano foram atendidos: a utilização de camas baixas, armários ao alcance da criança, espelho, estante baixa ou nichos para guardar os brinquedos, quadros, desenhos e objetos a altura para que a criança possa apreciar e o cantinho da leitura.

Nas figuras 7, 8 e 9 tem-se a proposta 1: 0 apartamento está localizado na Rua Professor Raul Chaves, 246, Condomínio Verdes Mares, Patamares(10,70m²). 
Figura 7 - Planta falada do primeiro quarto

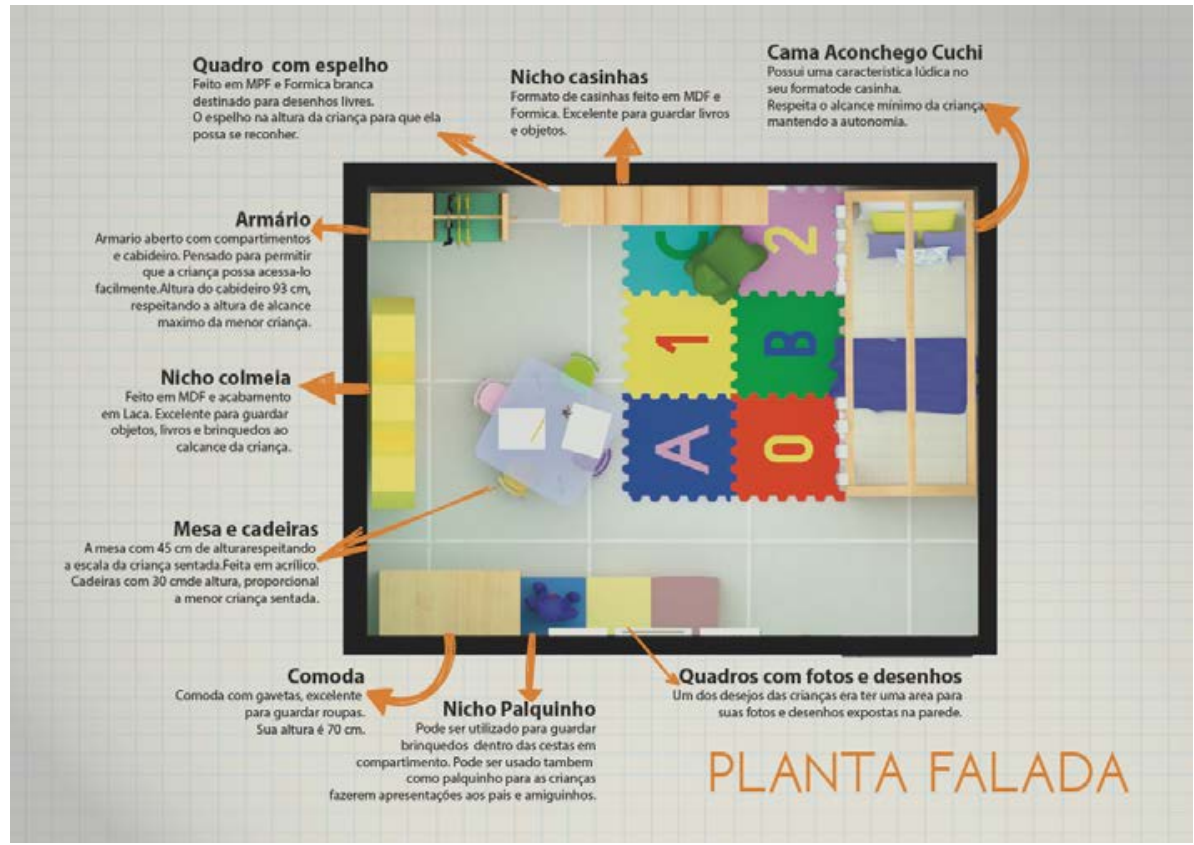

Fonte: acervo do autor, 2016.

Figura 8 - Vista em 3D do primeiro quarto

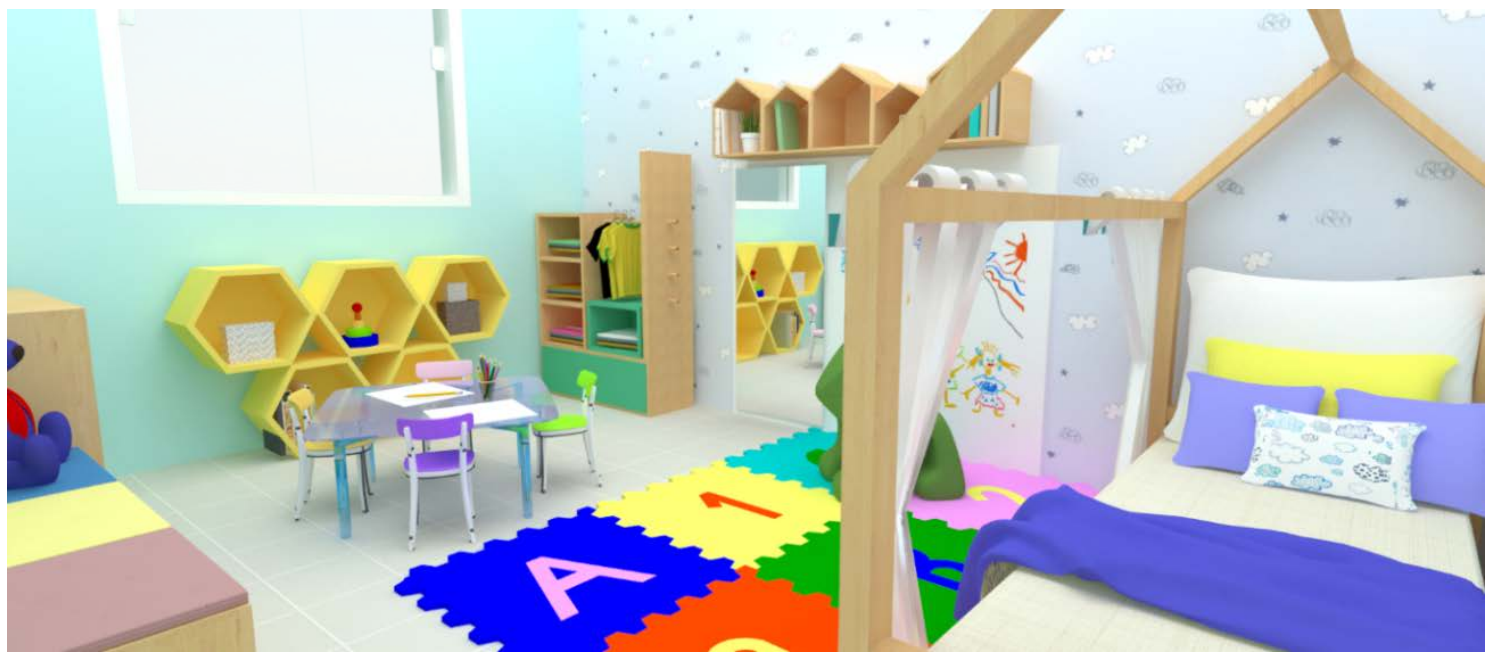

Fonte: acervo do autor, 2016. 
Figura 9- Outra vista em 3D do primeiro quarto

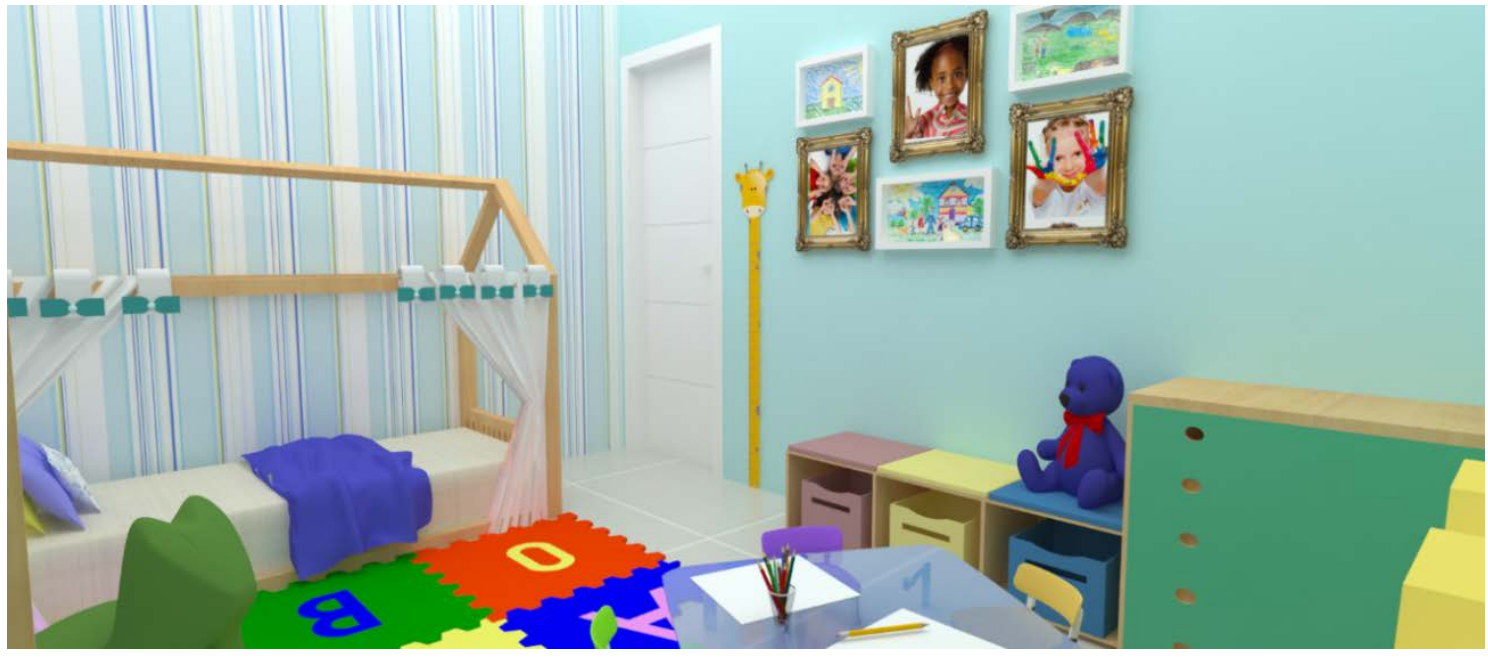

Fonte: acervo do autor, 2016.

Nas figuras 11, 12 e 13 tem-se a proposta 2: 0 apartamento está localizado na Alameda dos Flamboyants, Lt 64, Caminho das Árvores na cidade de Salvador(10m²).

Figura 11 - Planta falada do segundo quarto

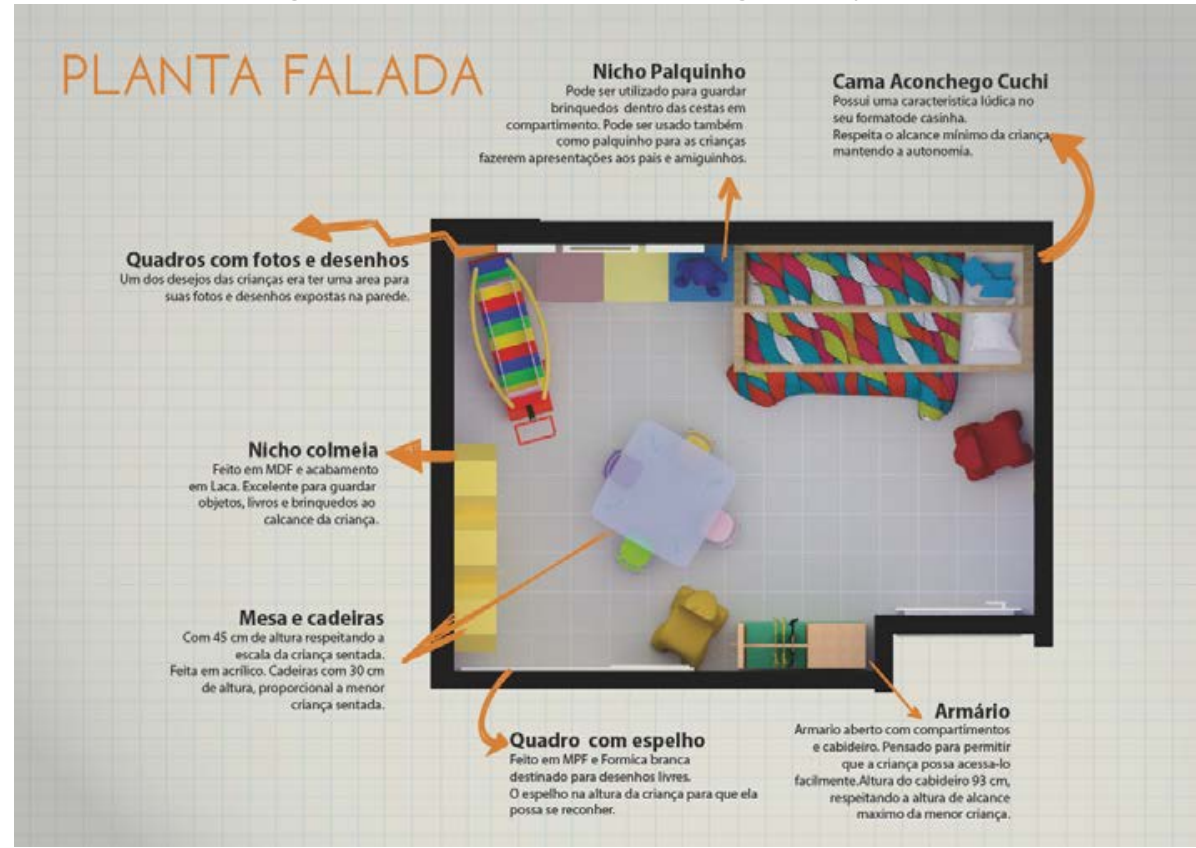

Fonte: acervo do autor, 2016. 
Figura 12- Vista e m 3D do segundo quarto

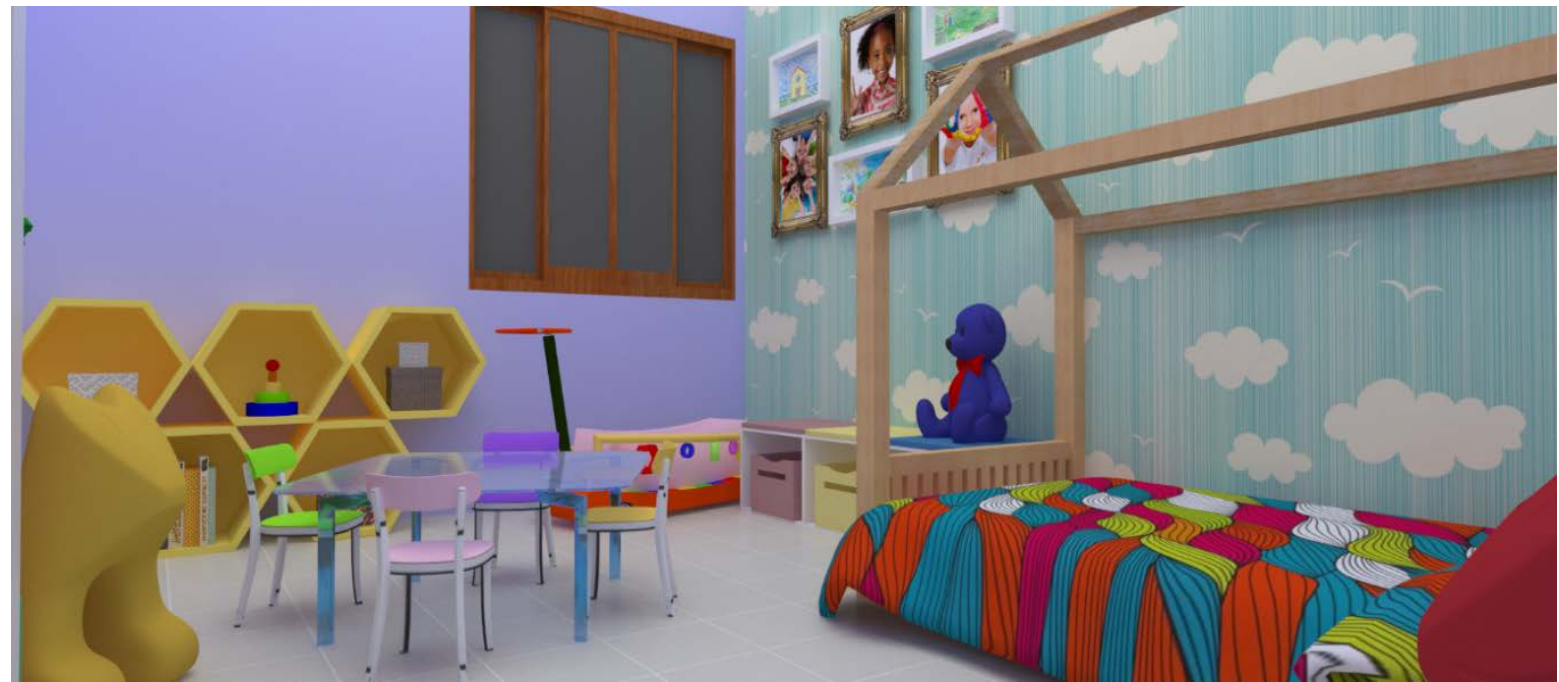

Fonte: acervo do autor, 2016

Figura 13- Vista e m 3D do segundo quarto

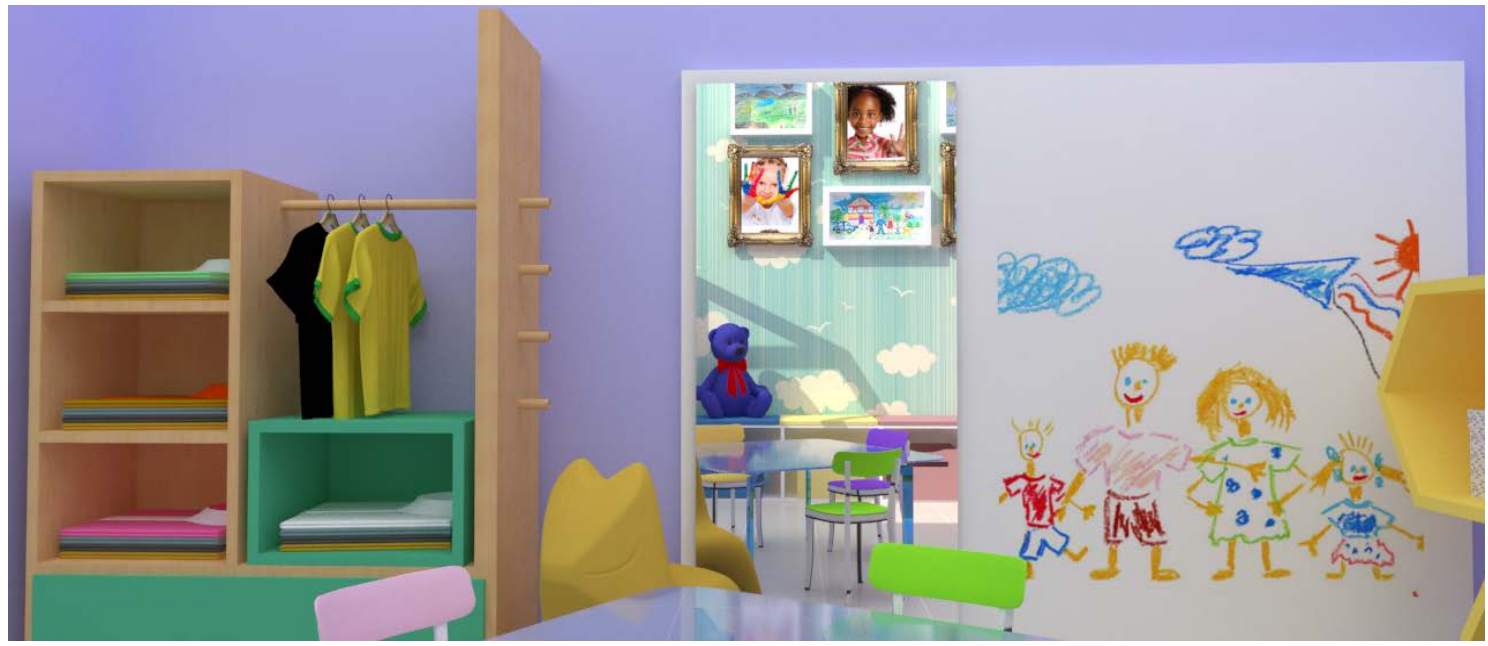

Fonte: acervo do autor, 2016.

Nas figuras 14, 15 e 16 tem-se a terceiraalternativa: um apartamento localizado na Avenida Ulisses Guimarães, s/n, Sussuarana, Salvador Life III - Bloco J(6,84 m²). 
Figura 14- Planta falada do terceiro quarto

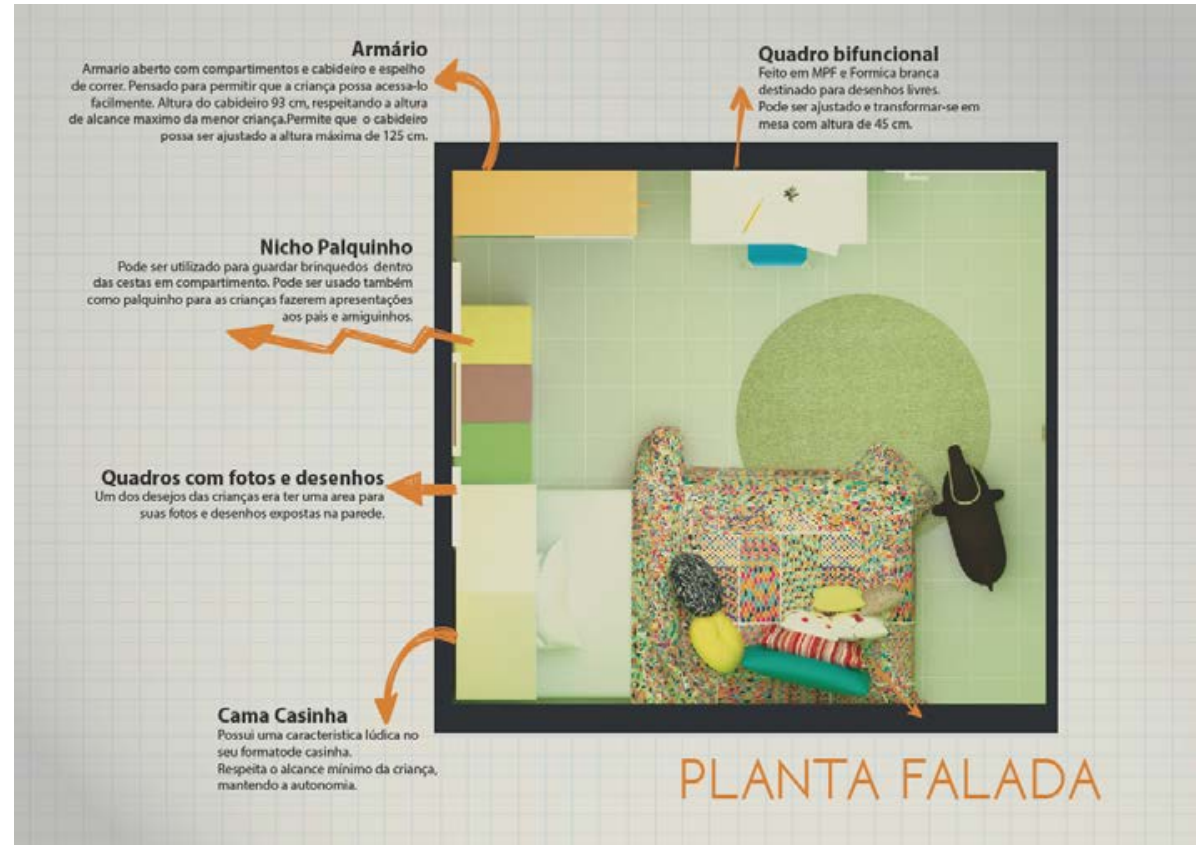

Fonte: acervo do autor, 2016.

Figura 15 - Vista em 3D do terceiro quarto

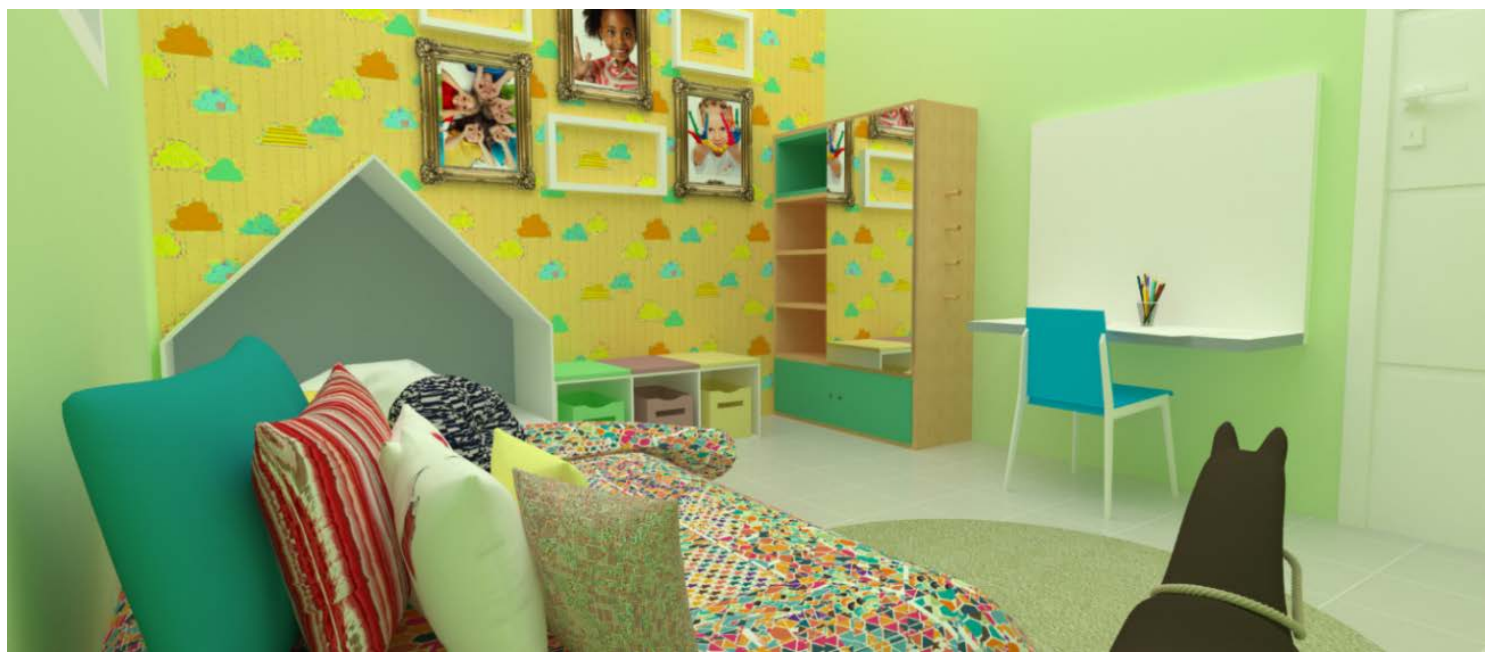

Fonte: acervo do autor, 2016. 
Figura 16-Outra vista em 3D do terceiro quarto

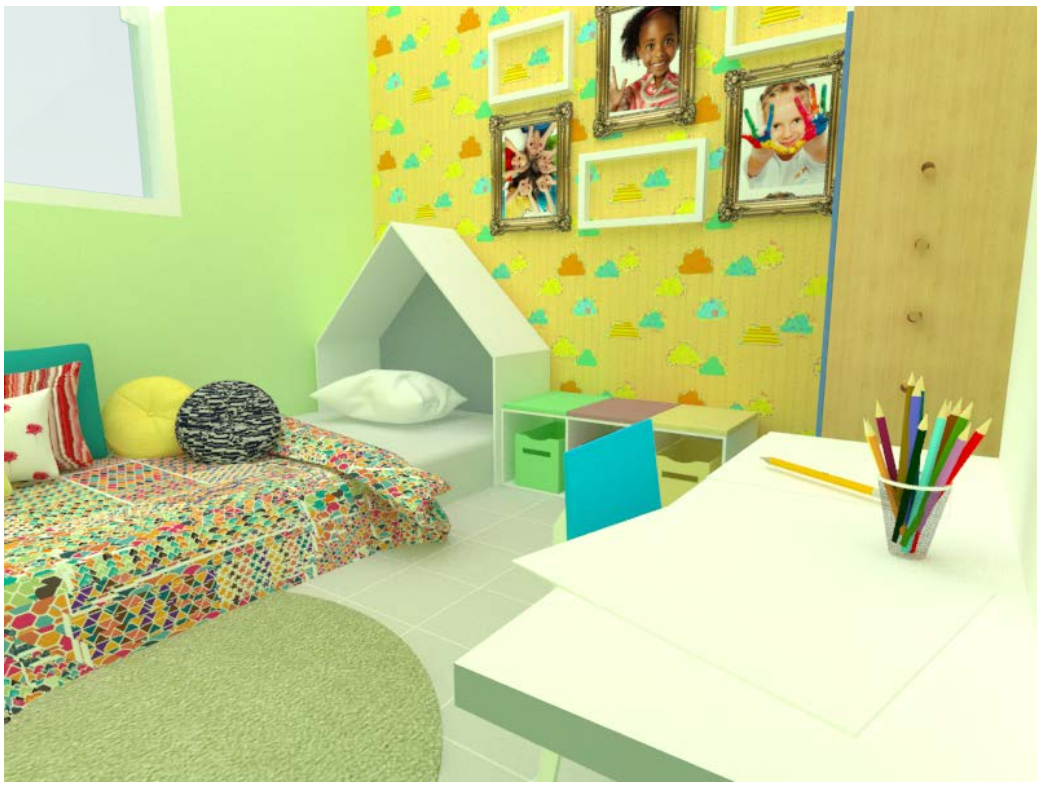

Fonte: acervo do autor, 2016.

Demonstra-se, portanto, que é possível atender aos princípios Motessorianos e aos desejos das crianças em tamanhos variados de quartos, compreendendo e acolhendo o universo infantil e principalmente promovendo o desenvolvimento autônomo, destes que amanhã serão adultos plenos na sociedade por meio do design de ambientes, subsidiado por estudos antropométricos e de métodos de viabilização da participação do usuário criança.

\section{Considerações finais}

A organização do quarto infantil, a disposição dos móveis e o acesso a eles são fatores indispensáveis para promoção da autonomia da criança nesse espaço, pois nele a criança irá vivenciar emoções, quea farão expressar sua maneira de pensar, onde será estimulado seu desenvolvimento e sua relação com o mundo.

No início dessa pesquisa foi gerada uma questão problema: "Como organizar os critérios Montessorianos em um quarto que atenda às necessidades da criança no que se refere a dar-lhe autonomia neste ambiente?" Nesta etapa de preconcepção do projeto foram desenvolvidas pesquisas para compreender o desenvolvimento da criança, como o espaço pode influenciar nesse desenvolvimento e estudados os critérios Montessorianos que foram empregados na criação do quarto infantil para promover a autonomia da criança. A etapa de preconcepção proporcionou boas respostas as perguntas que surgiram no início do projeto, essas respostas foram analisadas, com o objetivo de produzir a melhor alternativa definida para o projeto. Na etapa de Concepção foram produzidas alternativas de quartos que proporcionam autonomia da criança através da organização espacial deste ambiente. Na etapa de Pós-concepção foram apresentadas três propostas aplicadas em quartos de tamanhos diferentes. Estas propostas foram desenvolvidas e apresentadas em 3D.

Diversos são os modelos de quartos existentes nas casas das famílias brasileiras, assim também como uma variedade de móveis disponíveis no mercado, a escolha dos móveis e objetos 
e organização correta destes elementos no quarto é que podem proporcionar autonomia da criança, para favorecer seu desenvolvimento e aprendizado. As pesquisas continuarão e novos objetivos estão sendo gerados, poispercebeu-seexistir uma quantidade insuficiente de móveis projetados segundo a escala da criança. Concepção de móveis infantis adequado a escala do usuário criança é um desdobramento desse projeto,como também pesquisas mais aprofundadas para aplicar os critérios do método Montessoriano em outros ambientes.

\section{Referências}

BUITONI, Cassia Schroeder. Mayumi Watanabe Souza Lima: A construção do espaço para educação. 2009. 226 f. Dissertação (Mestrado) - Curso de Arquitetura e Urbanismo, Universidade de São Paulo, São Paulo, 2009.

DREYFUSS, Henry. Antropometria ou as medidas do homem, da mulher e da criança: variações humanas. In: DREYFUSS, Henry. As medidas do homem e da mulher: Fatores humanos em Design. Porto Alegre: Bookman, 2005. p. 3-6.

FARIA, Ana Lúcia Goulart de; PRADO, Patrícia Dias; DEMARTINI, Zelia de Brito Fabri. Por uma cultura de Infância:Metodologias de Pesquisa com crianças. 3. ed. São Paulo: Editora Autores Associados, 2009. 176 P.

MORAES, Anamaria de; ROSA, José Guilherme Santa.Design Participativo: Técnicas Para A Inclusão De Usuários No Processo Ergodesign De Interfaces. Rio de Janeiro: Rio Books, 2012. 169 p.

PANERO, Julius; ZELNIK, Martin. Dimensionamento Humano Para EspaçosInteriores: Um livro de consulta e referência para projetos. Barcelona, Espanha:Editorial Gustavo Gili, SL, 2002. P 30.

CUCHI (São Paulo). Cama Aconchego. Disponível em: <http://www.cuchi.com.br/camaAconchego>. Acesso em: 06 abr. 2016.

CUCHI (São Paulo). Armário Xá Comigo. Disponível em: <http://www.cuchi.com.br/armario-XaComigo>. Acesso em: 06 abr. 2016.

SEQUIN, Amanda. Casa Vogue: Mobiliário infantil é tendência na Semana do Design, em Milão. Disponível em: <http://casavogue.globo.com/Design/noticia/2016/04/mobiliario-infantil-etendencia-na-semana-do-design-em-milao.html>. Acesso em: 16 abr. 2016.

RABELLO, E.T. e PASSOS, J. S. Vygotsky e o desenvolvimento humano. Disponível em <http://www.josesilveira.com>. Acesso em: 8 out. 2015.

SALOMÃO, Gabriel. Lar Montessori: 0 quarto Montessoriano. 2012. Disponível em: <http://larmontessori.com/?s=o+quarto+montessori>. Acesso em: 05 nov. 2015.

SANTOS, Flávio Anthero Nunes Vianna. Método aberto de projeto para uso no ensino de Design Industrial. 2006. Disponível em: <http://www.redalyc.org/articulo.oa?id=66130104>. Acesso em: 5 nov. 2015. 